\title{
Analgesic effect of gabapentin in patients with carpal tunnel syndrome
}

\author{
Reza Sabet ${ }^{1}$, Karamatollah Rahmanian $^{2 *}$, Abdolreza Sotoodeh Jahromi ${ }^{1}$, Abdolhossein Madani ${ }^{3}$ \\ ${ }^{1}$ Research Center for Non-Communicable Diseases, Jahrom University of Medical Sciences, Jahrom, Iran. \\ ${ }^{2}$ Research Center for Social Determinants of health, Jahrom University of Medical Sciences, Jahrom, Iran. \\ ${ }^{3}$ Research Center for Social Determinants of health promotion, Hormozgan University of Medical Sciences, Bandarabbas, Iran.
}

\begin{tabular}{l}
\hline ARTICLE INFO \\
\hline Article history: \\
Received on: 14/02/2017 \\
Accepted on: 15/04/2017 \\
Available online: $30 / 06 / 2017$ \\
\hline Key words: \\
CTS, Gabapentin, Naproxen, \\
SSS Scale, FSS Scale.
\end{tabular}

\begin{abstract}
Introduction: Carpal tunnel syndrome (CTS) is a common condition that caused by entrapment of the median nerve in the wrist of hand. The aim of study was to assess the antinoceceptive effect of gabapentin in patients with CTS

Materials and Methods: We conducted a clinical trial recruiting patients with mild CTS for a period of more than three months. Fifty patients were enrolled in the study, of who 25 were randomly assigned togroup A and 25 to group B. CTS confirmed by electrophysiological tests. Patients in the group A received naproxen (starting dose $500 \mathrm{mg}$ once daily PO) and in the group B received combination therapy; gabapentin (starting dose $100 \mathrm{mg}$ once daily to a target of $300 \mathrm{mg}$ daily PO) and naproxen (starting dose $500 \mathrm{mg}$ once daily PO). Primary endpoint was the symptom severity scale (SSS) and functional state scale (FSS) which was measured at baseline and two months after treatment.

Results: There was no significant difference in baseline variables between the two treatment groups. Both groups produced significant improvement in symptoms at two months after treatment. The SSS and FSS at the end of two months was statistically significant difference in both study groups than before treatment. Also by two months, the mean reduction in SSS and FSS scale on group B was significant when compared with group A $(\mathrm{p}<0.001)$.

Conclusions: Combination therapy of Gabapentin and naproxen produced a significant reduction in symptom severity and functional state scale compared with naproxen alone over a two month period.
\end{abstract}

\section{INTRODUCTION}

The carpal tunnel syndrome (CTS) is caused by entrapment of the median nerve at the wrist and it is most common in women (Evanoff et al., 2016; Kilic et al., 2015; Kleopa 2015, Violante et al., 2016). Several managements of CTS include splinting, oral drugs, steroid injections, and surgery (Prime et al., 2010; Saboor et al., 2015), but efficacy of nonsurgical treatments showed to be short term benefit (Fernándezde-las-Peñas et al., 2017; Huisstede et al., 2010) or there is still little known about the efficacy of most conservative treatment options for CTS (Gerritsen et al., 2002). Surgery was shown to produce good relief of symptoms (Tran and Szabo, 2017), but it

\footnotetext{
* Corresponding Author

Karamatollah Rahanian, Research Center for Social Determinants

of health, Jahrom University of Medical Sciences, Jahrom, Iran.

Email: rahmaniank47@yahoo.com
}

has several disadvantages like pain and hand weakness (Banta, 1994). Nonsurgical treatments are alternatives to surgery but only steroids; acupuncture and splinting have shown noticeable benefits (O'Connor et al., 2003; Prime et al., 2010; Yang Chun-Pai et al., 2009a; Yang et al., 2009b). A recent study reported acupuncture and prednisolone to be an effective treatment without statistically significant difference between the two treatments (Yang et al., 2009b). The important non-surgical treatment is steroid injection (Atroshi et al., 2016). A systematic review by Marshal et al unable to show greater therapeutic benefits when compared to patients treated with oral anti-inflammatory medication and wrist splinting (Marshall et al., 2007). Previous studies have confirmed the effect of gabapentin on pain management after orthopedic surgery (Eloy et al., 2017; Khosravi et al., 2014; Mardani-Kivi et al., 2013) and in in recovery from neuropathic pain syndromes for example trigeminal neuralgia, neuropathy from diabetes, multiple sclerosis, and post-herpetic neuralgia (Finnerup et al., 2015; Levendoglu et al., 2004; Meng et al., 2014). 
Gabapentin was practiced in the treatment of CTS by several studies (Duman et al., 2008; Erdemoglu, 2009; Taverner et al., 2008). Taverner et al (Taverner et al., 2008) in a prospective study with a 6 month follow up starting treatment with 1800 $\mathrm{mg} /$ day of gabapentin were showed a statistically significant reduction of pain and improvement of severity of symptoms, but functional capacity did not change. In other study, those 49 patients with CTS managed with average dosage of gabapentin $1800 \mathrm{mg} /$ day, there was a statistically significant difference in both symptom SSS and FSS scores between before and after treatment at the end of six months (Erdemoglu, 2009). However, the evidence for its efficacy has established with in placebo-controlled trials only in one study. Hui and et al (Hui et al., 2011) conducted a randomized, double-blinded study with 140 patients (71 patients received $300 \mathrm{mg}$ once daily gabapentin and 69 patients received placebo). The symptom severity decreased significantly at 2 and 8 weeks in both gabapentin and placebo groups but, the mean reduction was not significant in two studied groups. The aim of study was to compare the value of gabapentin and combination therapy (gabapentin and naproxen) in the management of mild CTS.

\section{MATERIALS AND METHODS}

All participants in the study signed consciously and voluntarily consent form before entry.

The study was conducted to determine the effect of gabapentin on CTS. The Patients who had mild CTS for more than three months directed to the Honari Clinic, Jahrom, Iran, were selected.CTS diagnosis was established on clinical symptoms and electrophysiological study (Pekel et al., 2017; Wilder-Smith et al., 2006).

The Boston Carpal Tunnel Questionnaire (BCTQ) included two parts: Symptom Severity Scale (SSS) and Functional State Scale (FSS). Symptom severity was assessed by using the SSS and functional disability by using FSS. The SSS has 11 questions, the FSS 8 questions and both use a five-point scale. Each scale generates a final score (sum of individual item scores divided by number of items), which ranges from 1 to 5 . Each patient that selected score of $0-3$ to each questions included to study. Electrophysiological diagnosis of CTS was based on the criteria proposed by the American Academy of Neurology(Ubogu and Benatar 2006).

The SSS score of less than 3 and electro diagnostic criteria of $\mathrm{SNCV} \leq 40 \mathrm{~meter} / \mathrm{second}(\mathrm{m} / \mathrm{s})$ and distal motor latency $<4.4$ millisecond (ms) was as mild CTS.

Patients with previous steroid injection or surgery in the same wrist, thenar atrophy, pregnancy, severe medical diseases, sensitivity to gabapentin, positive history of gabapentin consumption, history psychiatric disorders, drugs and alcohol addiction, known liver or renal disease and the patients who had an intake of analgesic or anticonvulsant drugs one week before the test were excluded from the study. This quasi-experimental study was conducted as double-blind. In this study due to the small number of patients and lack of appropriate access method, 50 patients were selected over time. The first known cases of CTS randomly assigned to one of two treatment groups. Then the other patients in the study were assigned to other group. If the first patient was assigned to group $\mathrm{A}$, the second patient received drug of group B, third patient Group A, forth patient group B and so on respectively.

The group A received oralnaproxen alone (a non steroid anti- inflammatory drugs, $500 \mathrm{mg}$ orally, once daily), and the group B received combination therapy of oral gabapentin $(100 \mathrm{mg}$ orally once daily to a target of $300 \mathrm{mg}$ daily) and naproxen (500 mg orally once daily) for two months. Before the intervention, the following was recorded: demographic characteristics, electrophysiological evaluation and BCTQ assessment.

Two months after treatment, the participants visited to assess the response to treatment with the BCTQ.

\section{Statistical analyses}

After determine of data normality by Kolmogorov smirnov z-test, differences of each groups from pre-intervention data and between groups were compared by paired student t test and student t-test. The summary of the data is presented as mean \pm SD (Standard Deviation) and the statistical significance was reported when $\mathrm{P}$ value was $<0.05$.

\section{RESULT AND DISCUSSION}

The pre interventional characteristics are shown in Table 1. There are no difference significantly existed in variables for example age, sex, FSS scale, SNCV and DML between the two groups except for SSS scale. No patients were lost to follow up.

The mean of SSS and FSS scale before and after the treatment are shown in table 2. Both two type of treatment produced significant reduction in SSS and FSS scale before and at 2 months after treatment. The mean reduction in SSS $(0.75 \pm 0.38)$ in group B was significant when compared with in group A (SSS, $0.17 \pm 0.25)$ after treatment $(\mathrm{p}<0.001)$. Also, the mean reduction in FSS $(0.65 \pm 0.32)$ in group B was significantly difference $(\mathrm{p}<0.001)$ when compared with in group A (FSS, $015 \pm 0.19)$.

Our study indicated that the combination administration of gabapentin and naproxen is significantly associated with SSS and FSS reduction than administration of naproxen alone. The efficacy of gabapentin in compared to placebo or other drugs was searched only by one research that was shown to be effective for CTS, but its efficacy wasn't significant in compared to placebo (Hui et al., 2011).

Because in epilepsy and neuropathic pain exist a lot of similarities in pathophysiological and biochemical mechanisms responsible for the disease, treatment with gabapentin could be favorable. Because of the effectiveness in the other neuropathy, gabapentin is widely used for pain liberation. In our study, although two types of treatment created significant reduction in symptom liberation, a difference was significantly discovered between two groups. 
Table 1: Characteristic of both study groups.

\begin{tabular}{|c|c|c|c|}
\hline Study groups & Group A & Group B & P value \\
\hline Patient numbers & 25 & 25 & \\
\hline Sex; male, No (\%) & $4(16)$ & $7(28)$ & 0.306 \\
\hline Age; mean $\pm \mathrm{SD}$ & $42.24 \pm 8.67$ & $41.44 \pm 4.59$ & 0.686 \\
\hline Right hand involvement, No (\%) & $13(54.2)$ & $16(64.0)$ & 0.484 \\
\hline duration of symptoms, mean $\pm \mathrm{SD}$ & $17.96 \pm 6.84$ & $19.48 \pm 6.85$ & 0.436 \\
\hline SSS scale; mean \pm SD & $1.71 \pm 0.64$ & $2.04 \pm 0.47$ & 0.042 \\
\hline FSS scale; mean \pm SD & $1.29 \pm 0.53$ & $1.55 \pm 0.51$ & 0.085 \\
\hline SNCV; meter/second & $34.58(1.83)$ & $33.93(1.56)$ & 0.183 \\
\hline DML; millisecond & $4.18(0.18)$ & $4.13(0.09)$ & 0.103 \\
\hline
\end{tabular}

DML; Distal Motor Latency, FSS; Functional Status Scale, No; Number, SNCV; Sensory Nerve Conduction Velocity, SD; Standard Deviation, SSS; Symptom Severity Scale; Group A received naproxen alone and group B received gabapentin + naproxen.

Table 2: The mean and standard deviation of SSS and FSS scale in group A and B before and after the treatment

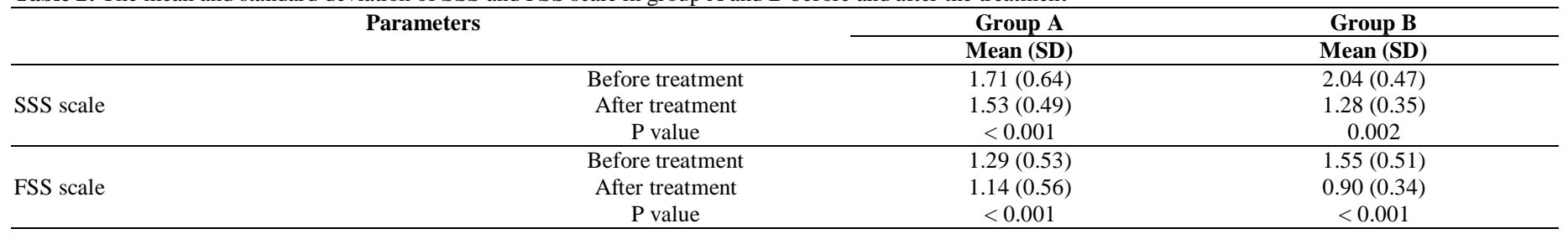

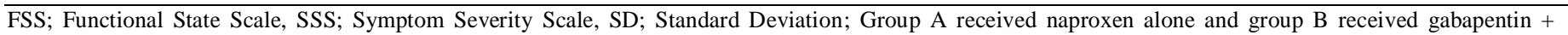
naproxen.

Previous studies suggested the favorable effects of gabapentin in CTS (Duman et al., 2008; Erdemoglu, 2009; Hui et al., 2011), but in our study is used a lower dose of gabapentin. In the first study, five patients in two groups were treated with gabapentin (mean dose of $1150 \mathrm{mg} /$ day) and with carbamazepine, separately. Both groups informed moderate symptomatic liberation (Facchetti et al., 1999). In studies conducted by Duman which 21 patients participated in the study that they received gabapentin at a dose of $648 \mathrm{mg}$ per day, who reported symptom relief after therapy and Erdemoglu reported that symptoms and functional status improved with gabapentin (at a higher median dosage of 1800 $\mathrm{mg} /$ day) in 41 patients with CTS (Duman et al., 2008; Erdemoglu, 2009). Only in one RCT study, Hui reported reduced symptoms in both gabapentin and placebo group but the mean reduction was not significant between both study groups (Hui et al., 2011). In present study, naproxen alone produces a substantial reduction in SSS and FSS scale.

The most important result of our study was the more efficacies of gabapentin + naproxen in compared to naproxen in both SSS and FSS scale with low dose of gabapentin. In our study, a lesser dose was taken to minimize contrary effects and to augment acceptability. Taverner in your study (Taverner et al., 2008) used a greater dose of gabapentin (1800 mg/day) and reported $28 \%$ of patients stopped using the medication forsome complications. Although Erdemoglu were seen side effects in $26.8 \%$ of patients ( $1800 \mathrm{mg} /$ day average dose of gabapentin), most of them were mild and tolerable (Erdemoglu, 2009).
Previous studies recommend that symptom release happened during the titration period even before the highest dose was reached (Duman et al., 2008; Hui et al., 2011).

\section{CONCLUSION}

As a result, we consider that advanced doses would not yield well effects, but would cause additional adverse responses. Carpal tunnel syndrome make happen through compression of the median nerve within the carpal tunnel, and as yet the most active therapy is targeted at decreasing the swelling by the injection of steroid or dissection of the flexor retinaculum (Peters-Veluthamaningal et al., 2010).

In present study, although, naproxen as a NSAIDS was caused reduction of pain during two-month treatment but combination therapy (Gabapentin + naproxen) were more effective for patients with mild CTS. But for usual use for CTS required to study with larger participants.

\section{ACKNOWLEDGEMENTS}

Financial support and sponsorship: This study was funded by Jahrom University of Medical Sciences.

Conflict of interests: There are no conflicts of interest. 


\section{REFRENCES}

Atroshi I, Hofer M, Ranstam J. Randomized Controlled Trial of Local Steroid Injection in Carpal Tunnel Syndrome: 5 Years Follow-up. Journal of Hand Surgery, 2016: 41:S46-S47.

Banta CA. A Prospective, Nonrandomized Study of lontophoresis, Wrist Splinting, and Antiinflammatory Medication in the Treatment of Early-Mild Carpal Tunnel Syndrome. Journal of Occupational and Environmental Medicine, 1994: 36:166-168.

Duman I, Aydemir K, Ozgul A, Kalyon TA. Assessment of the Efficacy of Gabapentin in Carpal Tunnel Syndrome. J Clin Rheumatol, 2008: 143:175-177.

Eloy JD, Anthony C, Amin S, Caparó M, Reilly MC, Shulman S. Gabapentin Does Not Appear to Improve Postoperative Pain and Sleep Patterns in Patients Who Concomitantly Receive Regional Anesthesia for Lower Extremity Orthopedic Surgery: A Randomized Control Trial. Pain Research and Management, 2017: 1-5

Erdemoglu AK. The efficacy and safety of gabapentin in carpal tunnel patients: open label trial. Neurol India, 2009: 57:300-303.

Evanoff B, Gardner BT, Strickland JR, Buckner-Petty S, Franzblau A, Dale AM. Long term symptomatic, functional, and work outcomes of carpal tunnel syndrome among construction workers. American journal of industrial medicine, 2016:59(5):357-68

Facchetti D, Chiroli S, Bascelli C, Sasanelli F. Gabapentin versus carbamazepine in conservative management of carpal tunnel syndrome. Neurology, 1999: 52(6):A203

Fernández-de-las-Peñas $\mathrm{C}$, Cleland $\mathrm{J}$, Palacios-Ceña $\mathrm{M}$, Fuensalida-Novo S, Pareja JA, Alonso-Blanco C. The Effectiveness of Manual Therapy Versus Surgery on Self-reported Function, Cervical Range of Motion, and Pinch Grip Force in Carpal Tunnel Syndrome: A Randomized Clinical Trial. Journal of Orthopaedic \& Sports Physical Therapy, 2017: 47:151-161.

Finnerup NB, Attal N, Haroutounian S, McNicol E, Baron R, Dworkin RH, Gilron I, Haanpää M, Hansson P, Jensen TS. Pharmacotherapy for neuropathic pain in adults: a systematic review and meta-analysis. The Lancet Neurology, 2015: 14:162-173.

Gerritsen AAM, de Krom MCTFM, Struijs MA, Scholten RJPM, de Vet HCW, Bouter LM. Conservative treatment options for carpal tunnel syndrome: a systematic review of randomised controlled trials. J Neurol, 2002: 249:272-280.

Hui AC, Wong SM, Leung HW, Man BL, Yu E, Wong LK. Gabapentin for the treatment of carpal tunnel syndrome: a randomized controlled trial. Eur J Neurol, 2011: 18:726-730.

Huisstede BM, Hoogvliet P, Randsdorp MS, Glerum S, van Middelkoop M, Koes BW. Carpal tunnel syndrome. Part I: effectiveness of nonsurgical treatments--a systematic review. Arch Phys Med Rehabil, 2010: 91:981-1004.

Khosravi MB, Azemati S, Sahmeddini MA. Gabapentin versus naproxen in the management of failed back surgery syndrome; a randomized controlled trial. Acta Anaesthesiol Belg,2014: 65:31-37.
Kilic B, Yucel AS, Yaman C, Catikkas F, Herguner G. Carpal Tunnel Syndrome. Advances in Environmental Biology, 2015:1-13.

Kleopa KA. Carpal tunnel syndrome. Annals of internal medicine, 2015: 163:ITC1-ITC1

Levendoglu F, Ogun CO, Ozerbil O, Ogun TC, Ugurlu H. Gabapentin Is a First Line Drug for the

Treatment of Neuropathic Pain in Spinal Cord Injury. Spine, 2004: 28:743-751.

Mardani-Kivi M, Mobarakeh MK, Keyhani S, Motlagh KH, Ekhtiari KS. Is gabapentin effective on pain management after arthroscopic anterior cruciate ligament reconstruction? A triple blinded randomized controlled trial. Arch Bone Jt Surg, 2013: 1:18-22.

Marshall S, Tardif G, Ashworth N. Local corticosteroid injection for carpal tunnel syndrome. Cochrane Database Syst Rev, 2007: 2:CD001554.

Meng FY, Zhang LC, Liu Y, Pan LH, Zhu M, Li CL, Li YW, Qian W, Liang R. Efficacy and safety of gabapentin for treatment of postherpetic neuralgia: a meta-analysis of randomized controlled trials. Minerva Anestesiol, 2014: 80:556-567.

O'Connor D, Marshall S, Massy-Westropp N. Non-surgical treatment (other than steroid injection) for carpal tunnel syndrome. Cochrane Database Syst Rev, 2003: 1:CD003219.

Pekel NB, Senol PN, Yildiz D, Kilic AK, Sener DK, Seferoglu M, Gunes A. The diagnostic efficacy of clinical findings and electrophysiological studies in carpal tunnel syndrome. The European Research Journal, 2017: 1-6.

Peters-Veluthamaningal C, Winters JC, Groenier KH, Meyboom-de Jong B. Randomised controlled trial of local corticosteroid injections for carpal tunnel syndrome in general practice. BMC Family Practice, 2010: 11:54-64.

Prime MS, Palmer J, Khan WS, Goddard NJ. Is there Light at the End of the Tunnel? Controversies in the Diagnosis and Management of Carpal Tunnel Syndrome. Hand, 2010: 5:354-360.

Saboor A, Khan A, Afridi SA, Khan IU, Bhatti SN, Ahmed E, Muhammad G, Khan RS, Sultan S, Lodhi FS. Early response of local steroid injection versus mini incision technique in treatment of carpal tunnel syndrome. Journal of Ayub Medical College Abbottabad, 2015: 27:192-196.

Taverner D, Lisbona MP, Segalés N, Docampo E, Calvet J, Castro S, Benito P. Efficacy of gabapentin in the treatment of carpal tunnel syndrome. Medicina Clinica, 2008: 130:371-373.

\section{How to cite this article:}

Sabet R, Rahmanian K, Jahromi AS, Madani A. Analgesic effect of gabapentin in patients with carpal tunnel syndrome. J App Pharm Sci, 2017; 7 (06): 079-082. 